\title{
SMR
}

\section{Identification of $C D 14$ transcript in blood polymorphonuclear neutrophil leukocytes and functional variation in Holsteins}

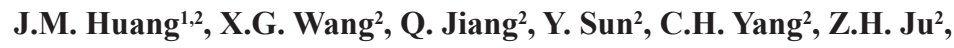 \\ H.S. Hao ${ }^{1}$, C.F. Wang ${ }^{2}$, J.F. Zhong ${ }^{2}$ and H.B. Zhu $^{1}$ \\ ${ }^{1}$ Embryo Biotechnology and Reproduction Laboratory, \\ Institute of Animal Sciences, Chinese Academy of Agricultural Sciences, \\ Beijing, China \\ ${ }^{2}$ Dairy Cattle Research Center, Shandong Academy of Agricultural Sciences, \\ Jinan, Shandong, China \\ Corresponding authors: J.M. Huang / H.B. Zhu \\ E-mail: huangjinm@sina.com / zhuhuabin@caas.cn \\ Genet. Mol. Res. 15 (2): gmr.15027932 \\ Received December 17, 2015 \\ Accepted January 15, 2016 \\ Published April 27, 2016 \\ DOI http://dx.doi.org/10.4238/gmr.15027932
}

\begin{abstract}
Polymorphonuclear neutrophil (PMN) leukocytes are primary phagocytic cells of the bovine mammary gland and a first line of defense against invading pathogens during bovine mastitis infection. Cluster of differentiation 14 (CD14) is mainly expressed in macrophages and neutrophils and acts as a co-receptor that binds bacterial lipopolysaccharide (LPS) and recruits PMNs to CD14-LPS complexes in mammary epithelial cells. In this study, we identified a novel splice variant in PMNs, named CD14-SV, characterized by a deleted region from c.143-579 nt compared to the CD14 reference mRNA sequence. Moreover, a single nucleotide polymorphism (c.523 A>G) in exon 2 of CD14 was identified and found to modify the secondary structure and hydrophilicity of the CD14 protein. Association analysis also showed that the milk somatic cell score, an indicator of mastitis, of cows with the GG genotype was lower than that of cows with the AA and AG
\end{abstract}


genotypes. Our findings suggest that the expression of $C D 14$ in bovine blood PMNs is regulated by alternative splicing, and that $C D 14-S V$ is a candidate functional marker that may influence mastitis-resistance in dairy cows.

Key words: $C D 14$; Splice variant; Functional SNP; Cow; Mastitis

\section{INTRODUCTION}

Mastitis is inflammation of breast tissue, and is responsible for huge economic losses in the dairy industry owing to its high incidence and the harm it causes. Mastitis not only reduces milk yield and impairs lactation in cows, it also affects milk quality and causes harm to human health. Approximately $90 \%$ of mastitis cases are caused by Streptococcus, Staphylococcus aureus, and Escherichia coli infections, and worldwide, annual losses due to mastitis infection are up to $\$ 35$ billion (Wellenberg et al., 2002). Although comprehensive prevention and control measures involving in the treatment of mastitis with antibiotics have been effective, these measures have led to the presence of drug residues in milk, the emergence of resistant bacterial strains, decreased milk quality, and have increased the cost of treatment.

At the early stage of tissue infection, innate immune responses are triggered, involving a variety of immune cells including macrophages, monocytes, and polymorphonuclear neutrophil (PMN), leukocytes, which are highly coordinated and comprise the first line of defense against the invading pathogens (Sibille and Reynolds, 1990; Silva, 2010). In healthy breast tissue, macrophages have leading and sentinel roles against foreign pathogens. However, when "invaders" are detected in breast tissue, immune cells release cytokines, which cause the subsequent migration of PMNs from the blood to the site of inflammation where they can kill the pathogens, representing a hallmark of the early immune response to infection (Paape et al., 2002; Zhang et al., 2015). Therefore, the number of effective PMNs is extremely important for immune defense in breast tissue. Molecular and conventional breeding methods have been used to select favorable mastitis resistance genes, or their genotypes, for use in genetic programs aiming to improve the ability of communities to resist mastitis, which is considered one of the best long-term strategies to reduce the incidence of mastitis (Heringstad et al., 2000; Zhang et al., 2015).

Alternative splicing, a basic and important eukaryotic regulatory mechanism, can generate alternatively spliced isoforms. This can affect the function and intracellular distribution of proteins, which is important during cellular differentiation and development, for physiological functions, and in pathological states (Eizirik et al., 2012; Gilboa-Geffen et al., 2012). In previous studies we showed that immune-related genes play important roles in bovine mastitis via alternative splicing (Huang et al., 2011; Hou et al., 2012; Li et al., 2013; Wang et al., 2014; Zhang et al., 2015). Cluster of differentiation 14 (CD14) is located on monocytes, macrophages, neutrophils, and plasma cells. It binds lipopolysaccharide (LPS) on the surface of Gram-negative bacteria, and peptidoglycan (PGN) and lipoteichoic acid (LTA) on the surface of Gram-positive bacteria. The CD14-LPS complex then recruits PMNs to sites of inflammation and subsequently reduces breast damage caused by endotoxin (Sladek and Rysanek, 2006). Transgenic animals expressing soluble CD14 protein are protected against mammary gland infections caused by Gram-negative bacteria (Paape et al., 2002; Bannerman et al., 2003). Therefore, we hypothesized that CD14 expression might be regulated by 
alternative splicing and that it may have critical roles during mastitis caused by Escherichia coli infection in dairy cows.

In this study, we identified a novel CD14 splice variant by RT-PCR and analyzed the molecular mechanism that generated this variant. In addition, we identified a functional single nucleotide polymorphism (SNP) c.523 $\mathrm{A}>\mathrm{G}$ in the $C D 14$ gene and used bioinformatics to predict its potential functional significance. Association analysis between $C D 14$ genotypes and milk somatic cell score (SCS) indicated that the c.523 A>G-G allele could be used as a potential functional marker for breeding mastitis-resistance in dairy cows. These results suggest that alternative splicing of CD14 and its SNP could have important roles in the infection of mammary tissues.

\section{MATERIAL AND METHODS}

\section{Animals and samples}

Mammary tissue samples were obtained from first lactation Chinese Holstein cows from a standardized slaughter company in Jinan, Shandong, China. Healthy cows without clinical signs, such as redness, swelling, heat, or pain, were sampled. If the cows presented clinical symptoms and were found to have $E$. coli infection by positive bacterial culture, they were defined as having mastitis. Blood was collected from a vein in the mammary region of four healthy cows and four cows with mastitis, following the manufacturer protocol (TBDsciences, Tianjin, China). PMNs were then extracted from blood using a previously described protocol (Zhang et al., 2015). The isolated PMNs were subsequently identified using the Wright-Giemsa dye method (Yue et al., 2014).

\section{Cloning of the $C D 14$ coding region and identification of splice variants}

Total RNA was isolated from the extracted PMNs and cDNA was synthesized using random primers. A specific primer pair (CD14F: 5'-TAAAGGA AAGAATCCACAGTCCA-3', CD14R: 5'-CTGTTTAAGATTTTAATAAGGATGGG-3') designed by the NCBI Primer designing tool (http://www.ncbi.nlm.nih.gov/tools/primer-blast/) was used to amplify the mRNA sequence of the $C D 14$ gene. PCR was performed as previously described (Wang et al., 2012). In brief, the following program was used: $4 \mathrm{~min}$ at $94^{\circ} \mathrm{C}$, followed by 35 cycles of $94^{\circ} \mathrm{C}$ for $30 \mathrm{~s}$, between $60^{\circ}$ and $68^{\circ} \mathrm{C}$ designed 8 temperature gradients for $30 \mathrm{~s}$, and $72^{\circ} \mathrm{C}$ for $1 \mathrm{~min}$, and final extension at $72^{\circ} \mathrm{C}$ for $2 \mathrm{~min}$. PCR products were detected by electrophoresis on $2 \%$ agarose gel. Finally, PCR products were purified, isolated, and cloned into the pEASY-T3 Vector (TransGen, Beijing, China), which were sent to BGI company (Beijing, China) for sequencing. The splice variant was identified and confirmed as previously described (Hou et al., 2012).

\section{Real-time quantitative PCR detection}

Differences in the expression of $C D 14$ in PMNs extracted from healthy cows and those with mastitis were investigated by RT-qPCR. The expression level in each individual was normalized using the housekeeping gene $\beta$-actin. The RT-qPCR primer pairs for $C D 14$ and $\beta$-actin were as follows: CD14F1: 5'-AACTGACGCTTGAGGACCTG-3', CD14R1: 5'-GGACAG AGAGCTGCCATCAG-3'; $\beta$-actinF: 5'-GCACAATGAAGATCAAGATCATC-3', $\beta$-actinR: 
5'-CTAACAGTCCGCCTAGAAGCA-3'. The reaction conditions were as follows: $94^{\circ} \mathrm{C}$ for $5 \mathrm{~min} ; 40$ cycles at $94^{\circ} \mathrm{C}$ for $15 \mathrm{~s} ; 60^{\circ} \mathrm{C}$ for $5 \mathrm{~s}$. Relative levels of gene expression were determined using the $2^{-\Delta \Delta C t}$ method, as previously described (Wang et al., 2012).

\section{Bioinformatics analysis}

To determine why $C D 14$ produced a novel splice variant, we analyzed the sequence characteristics of the CD14-SV splice variant using SROOGLE software online (http://sroogle.tau.ac.il/). The secondary structure and hydrophilicity of CD14 protein was predicted by DNAStar Protean software using the Garnier-Robson method (Cheng et al., 2012).

\section{Statistical analyses}

Associations between CD14 genotypes and SCS of cows were analyzed by the least squares method as applied in the GLM procedure of SAS 9.0. A modified procedure for the association analysis based on a previous report (Wang et al., 2014) was as follows:

$$
\mathrm{Y}_{\mathrm{ijklmn}}=\mu+\mathrm{F}_{\mathrm{i}}+\mathrm{G}_{\mathrm{j}}+\mathrm{S}_{\mathrm{k}}+\mathrm{E}_{1}+\mathrm{P}_{\mathrm{m}}+\mathrm{e}_{\mathrm{ijklmn}}
$$

where $Y_{i j k l m n}$ was the observed value; $\mu$ was the overall mean; $F_{i}$ was the fixed effect of farm; $\mathrm{G}_{j}$ was the fixed effect of genotype; $\mathrm{S}_{\mathrm{k}}$ was the fixed effect of sire; $\mathrm{E}_{1}$ was the fixed effect of season; $\mathrm{P}_{\mathrm{m}}$ was the fixed effect of parity; $\mathrm{e}_{\mathrm{ijk} k \mathrm{mn}}$ was the random residual effect. Values of $\mathrm{P}<$ 0.05 were considered significant.

\section{RESULTS}

\section{Identification of the CD14 splice variant, $C D 14-S V$}

PMNs were isolated from blood taken from the mammary veins of cows (Figure 1), and mRNA was extracted and subjected to RT-PCR analysis. Specific primers based on the NCBI CD14 mRNA reference sequence (NM_174008.1), named CD14F and CD14R and located in the 5' untranslated region (5'UTR) and 3'UTR, respectively, were used to amplify the coding region of the bovine $C D 14$ gene using cDNA from blood neutrophils. Interestingly, in addition to the expected 1312-bp PCR product, a smaller band was detected by electrophoresis on $2 \%$ agarose gel (Figure 2), which indicated a potential novel splice variant of the bovine $C D 14$ gene.

To verify the putative splice variant of the bovine $C D 14$ gene, we extraction, cloned, and sequenced the smaller band. As a result, a new splice variant, named CD14-SV, was identified by analysis of the BLAST alignment. CD14-SV was found to lack part of the sequence (c.143-579 nt) of the CD14 mRNA (Figure 3). 


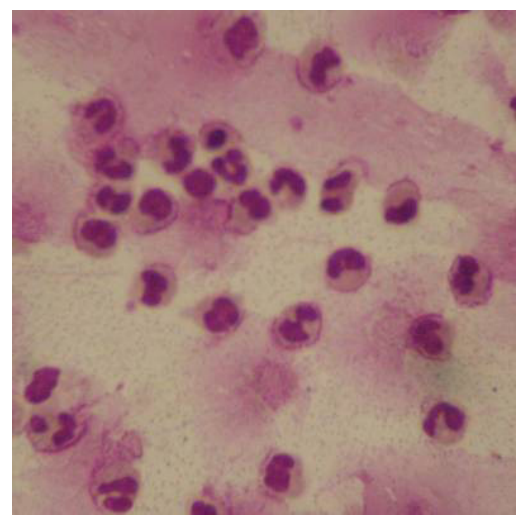

Figure 1. Identification of isolated polymorphonuclear neutrophils (PMNs) leukocytes. The isolated PMNs are identified by Wright-Giemsa dye.

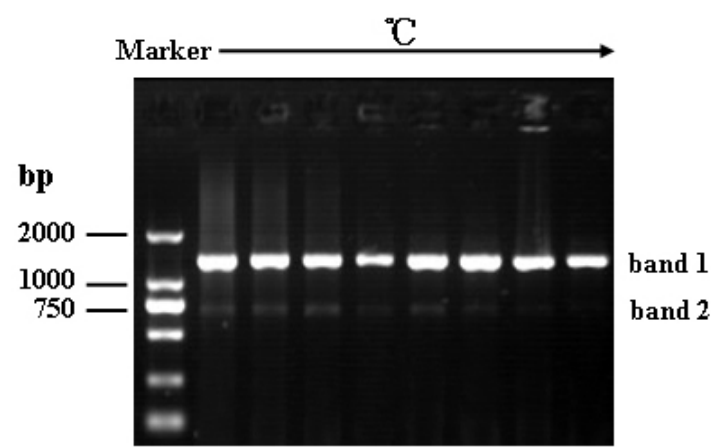

Figure 2. RT-PCR products of the CD14 gene in isolated bovine blood neutrophils. Band 1, predicted 1312-bp PCR product. Arrow, increase in annealing temperature for RT-PCR. Band 2, smaller band. Marker, DNA Marker 2000.

A

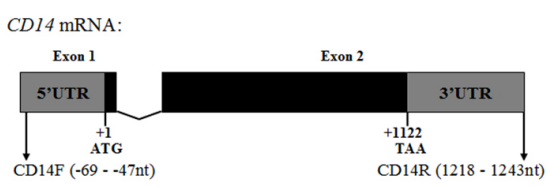

B

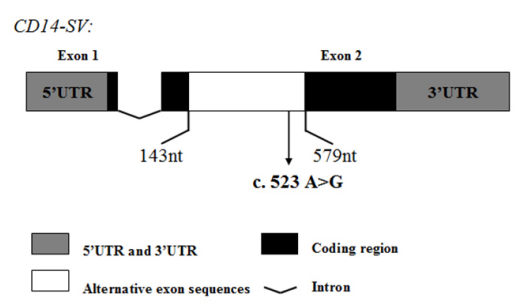

Figure 3. Identification of the novel splice variant, $C D 14-S V$. A. Genome structure of bovine CD14 mRNA. The CD14 gene consists of two exons, producing a 1122-bp coding region sequence. The positions of the CD14F and CD14R primers are indicated by black arrows. B. The sequence characteristics of the splice variant $C D 14-S V$. The $C D 14-S V$ transcript lacks a region from 143 to $579 \mathrm{nt}$ of exon 2 of the complete CD14 mRNA. The position of A nucleotide in the start codon (ATG) is defined as the +1 . 


\section{Expression of the CD14 gene in PMN}

Relative expression of $C D 14$ in PMNs isolated from four healthy cows and four cows with mastitis caused by E. coli was investigated by RT-qPCR using CD14F1 and CD14R1 primers. The results showed that PMNs isolated from cows with mastitis expressed CD14 at higher levels (6.36-fold) than those isolated from healthy cows (Figure 4).

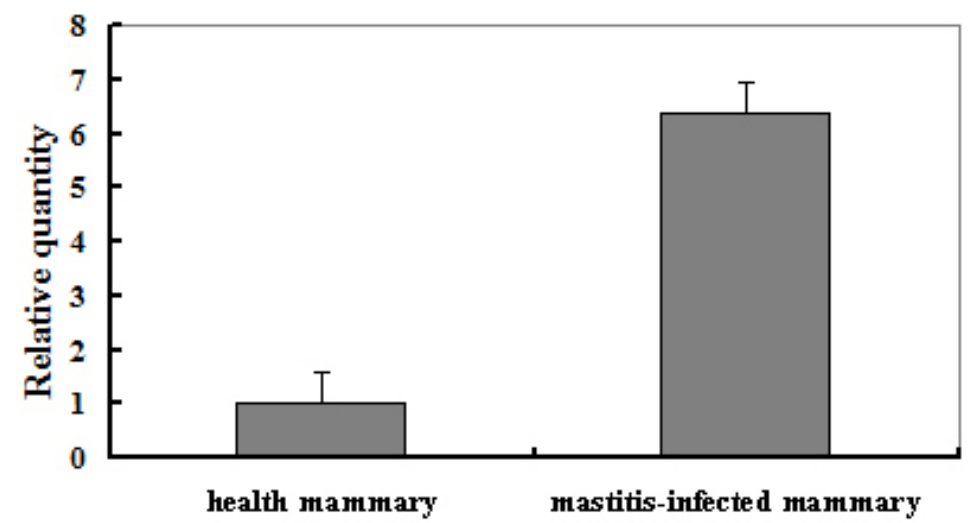

Figure 4. Relative expression of the $C D 14$ transcript in PMNs from healthy cows and cows with mastitis. Expression of the $C D 14-S V$ transcript was analyzed in different tissues by RT-qPCR. $\beta$-actin was used as the internal control. Healthy mammary: PMNs from healthy cows. Mastitis mammary: PMNs from cows with mastitis. Analyses were performed in triplicate.

\section{Analysis of the CD14 alternative splicing}

The above results showed that the sequence of $C D 14-S V$ was 143-579 nt shorter than that of the complete CD14 mRNA. To investigate how the novel splice variant CD14-SV was produced, SROOGLE software was used to predict the sequence characteristics of the $C D 14$ gene. Interestingly, close to c.143 and c.579 nt, the shorter CD14-SV mRNA sequence was predicted to contain DNA elements and regulatory protein combing sites involved in alternative splicing, including a branch site, a polypyrimidine tract, and $3{ }^{\prime}$ and $5^{\prime}$ splice sites, as well as other splice sites (Figure 5). Our findings indicate that these could contribute to the production of $C D 14-S V$. Analyses were performed in triplicate.

\section{Functional significance of the single nucleotide polymorphism}

Following amplification of the $C D 14$ gene using the CD14F and CD14R primers, we identified a SNP, c.523 A>G, in exon 2 (Figure 3B), which encoded a missense mutant (Pro.175 Asn $>$ Asp) (Figure 6). Furthermore, the secondary structure and hydrophilicity of the CD14 protein was predicted by DNAStar Protean software using the GarnierRobson method. Interestingly, the amino acid change at position 175 in allele G (Asn $\rightarrow$ Asp), resulted in the secondary structure of CD14 presenting a longer a-helix, a shorter $\beta$-pleated sheet, with no change in hydrophilicity. These data suggest that this SNP affects CD14 protein structure. 


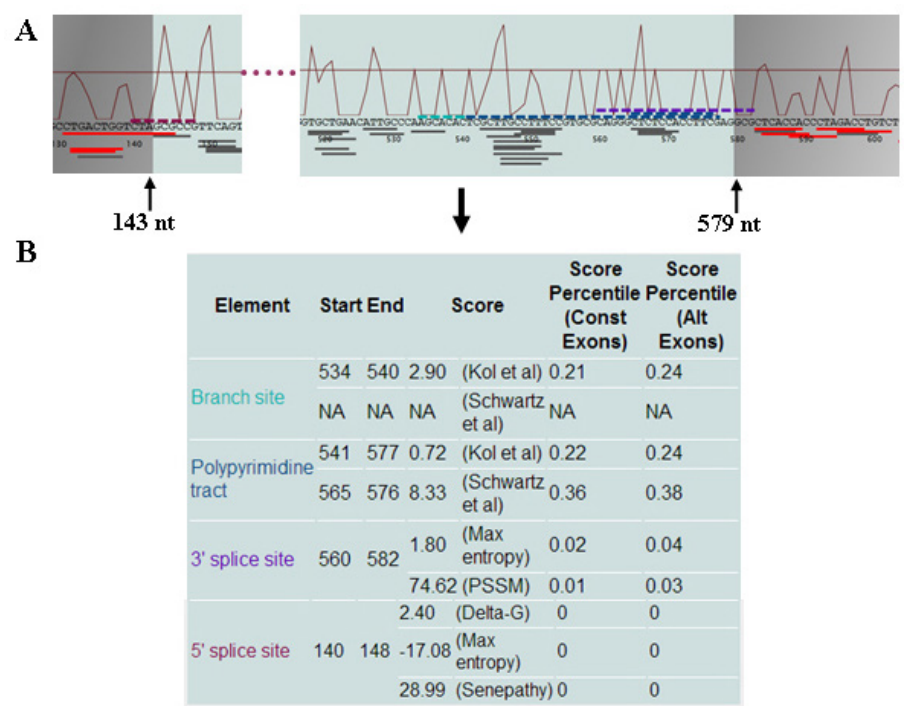

Figure 5. Sequence characteristics of the splice variant $C D 14-S V$. A. Results obtained using SROOGLE software. Different elements are represented by dashed annotations above the sequence, and sequence sites combined by many splicing regulatory proteins are annotated beneath the sequence. B. Splice site scores of the DNA element involved in pre-mRNA splicing. Previous reports on the sequence elements are listed in the table. Arrows indicate the position of $C D 14-S V$ alternative splicing.

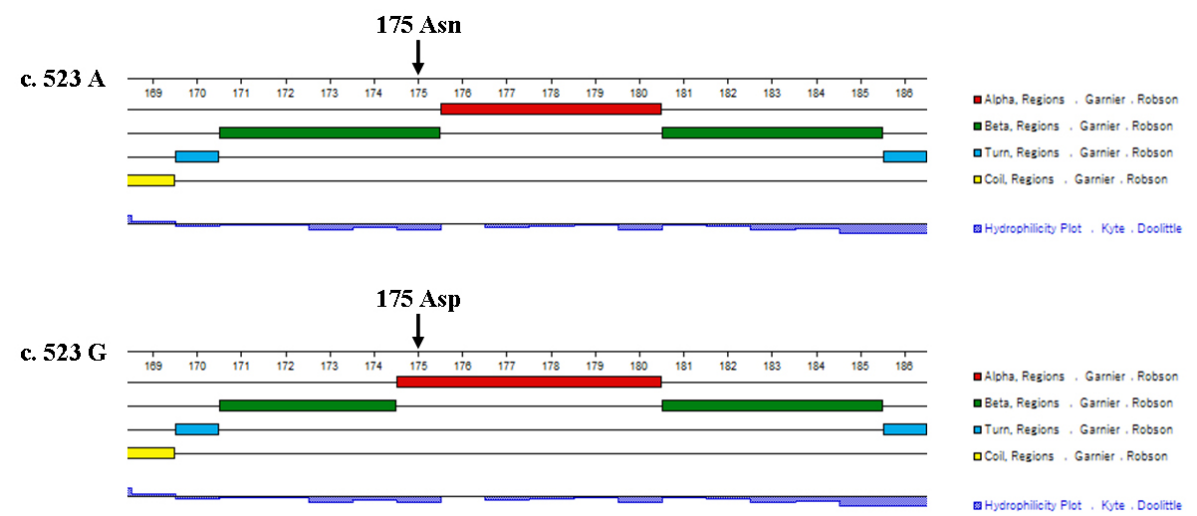

Figure 6. Prediction of the secondary structure and hydrophilicity of CD14. The 175 Asn $\rightarrow$ Asp in allele G resulted in CD14-SV being one a-helix longer and one B-pleated sheet shorter.

\section{Relationship between different genotypes and milk SCS in cow}

During mammary gland infection, somatic cells enter the milk; therefore, somatic cell count (SCC) is considered to be an indicator of dairy cow mastitis (Koivula et al., 2005). However, SCC is often converted into SCS owing to the usual skewness of its distribution frequency (Huang et al., 2010). To determine whether the SNP in CD14 plays a role in resistance to mastitis in dairy cows, we genotyped 300 Chinese Holstein for this SNP using 
the CD14F1 and CD14F1 primers by direct sequencing. The association analysis performed between different genotypes and SCS in 300 Chinese Holstein cows revealed that the frequencies of the A- and G-alleles were 55 and $45 \%$, respectively. Moreover, cows with the GG genotype showed a relatively lower SCS than those with the AA and AG genotypes ( $\mathrm{P}<$ 0.05 ) (Table 1), indicating that the G-allele in the c.523 position might have positive effects on mastitis resistance in cows.

Table 1. Association analysis between different genotypes and somatic cell score (SCS) in Chinese Holstein
cows.
\begin{tabular}{l|c|c|c|c}
\hline Genotype & Sample number & Genotypic frequency & Allelic frequency & SCS \\
\hline AA & 102 & 0.34 & $0.55(\mathrm{~A})$ & $4.91 \pm 0.33^{\mathrm{a}}$ \\
\hline AG & 124 & 0.41 & & $4.34 \pm 0.35^{\mathrm{a}}$ \\
\hline GG & 74 & 0.25 & $0.45(\mathrm{G})$ & $3.56 \pm 0.45^{\mathrm{b}}$ \\
\hline
\end{tabular}

Different superscript letters denote differences at $\mathrm{P}<0.05$.

\section{DISCUSSION}

During infection, PMNs migrate from the circulation to the lumen of the mammary gland, acting as a first line of defense against the invading pathogens (Kobayashi et al., 2003; Appelberg, 2007). CD14 recruits PMNs to sites of inflammation where they subsequently reduce tissue damage; therefore, CD14 plays a crucial role in infection and inflammation (Ziegler-Heitbrock, 2007). In this study, we found that the CD14 gene was expressed at significantly higher levels in blood PMNs from cows with mastitis than in those from healthy cows. Additionally, we identified a novel splice variant, named CD14-SV, in PMNs isolated from cattle blood, as well as a $\mathrm{SNP}(\mathrm{c} .523 \mathrm{~A}>\mathrm{G})$ in the $C D 14$ gene.

The process of gene pre-mRNA splicing is complex, and involves many small nuclear ribonucleoprotein particles and other non-snRNP splicing factors (Blencowe, 2000; Smith and Valcárcel, 2000; Cáceres and Kornblihtt, 2002). Additionally, conserved DNA sequences are also required for alternative gene splicing, which include the 5' splice site, branch site, pyrimidine tract, and 3' splice site (Hastings and Krainer, 2001; Wahl et al., 2009). In the present study, we used bioinformatics to predict the sequence characteristics of the CD14 gene to better understand the origin of the splice variant, $C D 14-S V$. Interestingly, the results revealed potentially conserved DNA elements and regulatory protein combing sites, including a branch site, polypyrimidine tract, and $3^{\prime}$ and $5^{\prime}$ splice sites, and other protein splice sites that could be associated with the alternative splicing of $C D 14$, close to the c.143 and c.579 nt splicing sites of CD14-SV. Previous studies, including our report, showed that short conserved DNA elements are required for constitutive gene splicing (Wahl et al., 2009; Wang et al., 2014). These analyses suggested that potential factors within the sequence of the CD14 gene could be responsible for the production of the splice variant, $C D 14-S V$.

Moreover, to verify whether the exonic SNP altered the structure or function of the CD14 protein, we analyzed the coding amino acids corresponding to the A and G allele at position c.523 and identified Asn and Asp, respectively. Furthermore, secondary structure and hydrophilicity of the CD14 protein with different amino acids were predicted by DNAStar Protean software. These analyses revealed that the secondary structure of CD14 containing Asn $\rightarrow$ Asp had an additional a-helix and lacked a $\beta$-pleated sheet. Recent evidence has indicated that SNPs can cause diseases by affecting the secondary structure of proteins (Kusuma et al., 2011; Al Rayyan et al., 2013; Roosing et al., 2013). To further investigate the 
functional significance of this SNP in bovine mastitis, we performed an association analysis between different genotypes and SCS. The results showed that cows with the GG genotype had lower SCS compared to those with the AA and AG genotypes. These data suggest that the GG genotype might play an important role in mastitis-resistance, and that it could be used as a functional molecular marker in dairy cow breeding.

In conclusion, we have identified a novel splice variant of the bovine $C D 14$ gene, named $C D 14-S V$, and analyzed the potential reason for its production using bioinformatics. In addition, we identified a novel SNP and used bioinformatics to predict its functional significance, and association analyses to investigate the relationship between genotype and SCS. These results require further experimental confirmation. This study provides evidence that alternative gene splicing is influenced by characteristics of conserved sequences, confirms the important role of SNPs in exonic gene regions, and provides a potential marker for molecular breeding against mastitis in dairy cow farming.

\section{Conflicts of interest}

The authors declare no conflict of interest.

\section{ACKNOWLEDGMENTS}

Research supported by grants from the National Natural Science Foundation of China (\#31401049, \#31371255, and \#31271328), and the Agricultural Science and Technology Innovation Program (\#ASTIP-IAS06).

\section{REFERENCES}

Al Rayyan N, Wankhade UD, Bush K and Good DJ (2013). Two single nucleotide polymorphisms in the human nescient helix-loop-helix 2 (NHLH2) gene reduce mRNA stability and DNA binding. Gene 512: 134-142. http://dx.doi. org/10.1016/j.gene.2012.09.068

Appelberg R (2007). Neutrophils and intracellular pathogens: beyond phagocytosis and killing. Trends Microbiol. 15: $87-$ 92. http://dx.doi.org/10.1016/j.tim.2006.11.009

Bannerman DD, Paape MJ, Hare WR and Sohn EJ (2003). Increased levels of LPS-binding protein in bovine blood and milk following bacterial lipopolysaccharide challenge. J. Dairy Sci. 86: 3128-3137. http://dx.doi.org/10.3168/jds. $\underline{\text { S0022-0302(03)73914-9 }}$

Blencowe BJ (2000). Exonic splicing enhancers: mechanism of action, diversity and role in human genetic diseases. Trends Biochem. Sci. 25: 106-110. http://dx.doi.org/10.1016/S0968-0004(00)01549-8

Cáceres JF and Kornblihtt AR (2002). Alternative splicing: multiple control mechanisms and involvement in human disease. Trends Genet. 18: 186-193. http://dx.doi.org/10.1016/S0168-9525(01)02626-9

Cheng J, Li J, Zhang W, Cai Y, et al. (2012). Mutations in lipopolysaccharide-binding protein (LBP) gene change the susceptibility to clinical mastitis in Chinese Holstein. Mol. Biol. Rep. 39: 9601-9612. http://dx.doi.org/10.1007/ s11033-012-1824-4

Eizirik DL, Sammeth M, Bouckenooghe T, Bottu G, et al. (2012). The human pancreatic islet transcriptome: expression of candidate genes for type 1 diabetes and the impact of pro-inflammatory cytokines. PLoS Genet. 8: e1002552. http:// dx.doi.org/10.1371/journal.pgen.1002552

Gilboa-Geffen A, Hartmann G and Soreq H (2012). Stressing hematopoiesis and immunity: an acetylcholinesterase window into nervous and immune system interactions. Front. Mol. Neurosci. 5: 30. http://dx.doi.org/10.3389/ $\underline{\text { fnmol.2012.00030 }}$

Hastings ML and Krainer AR (2001). Pre-mRNA splicing in the new millennium. Curr. Opin. Cell Biol. 13: 302-309. http://dx.doi.org/10.1016/S0955-0674(00)00212-X

Heringstad B, Klemetsdal G and Ruane J (2000). Selection for mastitis resistance in dairy cattle: a review with focus on the situation in the Nordic countries. Livest. Prod. Sci. 64: 95-106. http://dx.doi.org/10.1016/S0301-6226(99)00128-1 
Hou Q, Huang J, Ju Z, Li Q, et al. (2012). Identification of splice variants, targeted microRNAs and functional single nucleotide polymorphisms of the BOLA-DQA2 gene in dairy cattle. DNA Cell Biol. 31: 739-744. http://dx.doi. org/10.1089/dna.2011.1402

Huang J, Wang H, Wang C, Li J, et al. (2010). Single nucleotide polymorphisms, haplotypes and combined genotypes of lactoferrin gene and their associations with mastitis in Chinese Holstein cattle. Mol. Biol. Rep. 37: 477-483. http:// dx.doi.org/10.1007/s11033-009-9669-1

Huang J, Liu L, Wang H, Zhang C, et al. (2011). Variants and gene expression of the TLR2 gene and susceptibility to mastitis in cattle. Asian J. Anim. Vet. Adv. 6: 51-61. http://dx.doi.org/10.3923/ajava.2011.51.61

Li L, Huang J, Ju Z, Li Q, et al. (2013). Multiple promoters and targeted microRNAs direct the expressions of HMGB3 gene transcripts in dairy cattle. Anim. Genet. 44: 241-250. http://dx.doi.org/10.1111/age.12007

Kusuma L, Dinesh SM, Savitha MR, Krishnamurthy B, et al. (2011). A maiden report on CRELD1 single-nucleotide polymorphism association in congenital heart disease patients of Mysore, South India. Genet. Test. Mol. Biomarkers 15: 483-487. http://dx.doi.org/10.1089/gtmb.2010.0246

Kobayashi SD, Voyich JM and DeLeo FR (2003). Regulation of the neutrophil-mediated inflammatory response to infection. Microbes Infect. 5: 1337-1344. http://dx.doi.org/10.1016/j.micinf.2003.09.013

Koivula M, Mäntysaari EA, Negussie E and Serenius T (2005). Genetic and phenotypic relationships among milk yield and somatic cell count before and after clinical mastitis. J. Dairy Sci. 88: 827-833. http://dx.doi.org/10.3168/jds. $\underline{\text { S0022-0302(05) } 72747-8}$

Paape M, Mehrzad J, Zhao X, Detilleux J, et al. (2002). Defense of the bovine mammary gland by polymorphonuclear neutrophil leukocytes. J. Mammary Gland Biol. Neoplasia 7: 109-121. http://dx.doi.org/10.1023/A:1020343717817

Roosing S, van den Born LI, Hoyng CB, Thiadens AA, et al. (2013). Maternal uniparental isodisomy of chromosome 6 reveals a TULP1 mutation as a novel cause of cone dysfunction. Ophthalmology 120: 1239-1246. http://dx.doi. org/10.1016/j.ophtha.2012.12.005

Sibille Y and Reynolds HY (1990). Macrophages and polymorphonuclear neutrophils in lung defense and injury. Am. Rev. Respir. Dis. 141: 471-501. http://dx.doi.org/10.1164/ajrccm/141.2.471

Silva MT (2010). When two is better than one: macrophages and neutrophils work in concert in innate immunity as complementary and cooperative partners of a myeloid phagocyte system. J. Leukoc. Biol. 87: 93-106. http://dx.doi. org $/ 10.1189 / \mathrm{jlb} .0809549$

Sladek Z and Rysanek D (2006). The role of CD14 during resolution of experimentally induced Staphylococcus aureus and Streptococcus uberis mastitis. Comp. Immunol. Microbiol. Infect. Dis. 29: 243-262. http://dx.doi.org/10.1016/j. cimid.2006.06.006

Smith CWJ and Valcárcel J (2000). Alternative pre-mRNA splicing: the logic of combinatorial control. Trends Biochem. Sci. 25: 381-388. http://dx.doi.org/10.1016/S0968-0004(00)01604-2

Wahl MC, Will CL and Lührmann R (2009). The spliceosome: design principles of a dynamic RNP machine. Cell 136: 701-718. http://dx.doi.org/10.1016/j.cell.2009.02.009

Wang X, Huang J, Zhao L, Wang C, et al. (2012). The exon 29 c.3535A $>$ T in the alpha-2-macroglobulin gene causing aberrant splice variants is associated with mastitis in dairy cattle. Immunogenetics 64: 807-816. http://dx.doi. org/10.1007/s00251-012-0639-8

Wang X, Zhong J, Gao Y, Ju Z, et al. (2014). A SNP in intron 8 of CD46 causes a novel transcript associated with mastitis in Holsteins. BMC Genomics 15: 630. http://dx.doi.org/10.1186/1471-2164-15-630

Wellenberg GJ, van der Poel WH and Van Oirschot JT (2002). Viral infections and bovine mastitis: a review. Vet. Microbiol. 88: 27-45. http://dx.doi.org/10.1016/S0378-1135(02)00098-6

Yue QF, Xiong B, Chen WX and Liu XY (2014). Comparative study of the efficacy of Wright-Giemsa stain and Liu's stain in the detection of Auer rods in acute promyelocytic leukemia. Acta Histochem. 116: 1113-1116. http://dx.doi. org/10.1016/j.acthis.2014.05.005

Zhang Z, Wang X, Li R, Ju Z, et al. (2015). Genetic mutations potentially cause two novel NCF1 splice variants upregulated in the mammary gland, blood and neutrophil of cows infected by Escherichia coli. Microbiol. Res. 174: 24-32. http://dx.doi.org/10.1016/j.micres.2015.03.005

Ziegler-Heitbrock L (2007). The CD14+ CD16+ blood monocytes: their role in infection and inflammation. J. Leukoc. Biol. 81: 584-592. http://dx.doi.org/10.1189/jlb.0806510 